\title{
Does Identity and Integration Cause Muslims to Choose to Support Celtic Football Club?
}

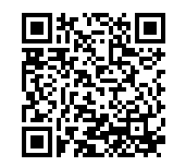

\author{
Christopher Farrell, Kieran James* \\ University of the West of Scotland, Paisley campus, Scotland
}

Submission: September 06, 2019; Published: September 24, 2019

*Corresponding author: Kieran James, School of Business and Enterprise, University of the West of Scotland, Paisley campus, Scotland

\section{Abstract}

Substantial literature has been written regarding whether UK Muslims identify as British or Muslim. However, there appears to be a lack of research surrounding how these sentiments, in conjunction with other key determinants, impact on the decision as to which football team they support. This research will attempt to examine how identity is formed, how integration is achieved, and determine whether Muslims feel an affiliation towards Irish-Scots backed Celtic FC due to both groups sharing a minority status in Scotland. The present article comprises a literature review only and further research findings will be released in due course.

Keywords: Celtic Football Club; Football; Glasgow; Muslim identity; Muslim integration; Old Firm; Scotland; Soccer

\section{Introduction}

A motivation for this article's topic arose from the realization that very little research has been carried out about Muslim communities in Scotland, let alone how their feelings of identity and integration into wider society have influenced their decisionmaking how they choose which football team to support. I start with a brief look at what a literature review is and the reasons why it is written. Next, a summarized look at Muslim numbers in Britain, according to the National Census, is carried out. In the main body of this article, with the help of existing studies and empirical evidence, a review of the literature is performed on how Muslims in general have integrated into society and how Muslims in the UK have integrated into Britain's cultural norms. This is followed by a review of the main existing literature regarding how Muslims primarily come to view themselves in the context of either being British, Scottish, and/or Muslim. Finally, a brief review is done on how supporters of Celtic FC (sometimes referred to as Glasgow Celtic FC), comprising mostly of third- or fourth-generation Irish immigrants, view their identities according to existing literature. In doing so, a better sense can be made of the research findings which will come later.

\section{Literature Review}

Before writing a literature review, it is important to understand what it is and why it is done. At this point it should be stated that for the purpose of this piece of work a traditional literature review style has been chosen.

A literature review is a logically structured written appraisal of existing knowledge on a subject, with emphasis on describing, building on, then bringing together said knowledge with the added dimension of the writer's interpretation. It shows the reader that you are aware of what has already been written; the reasons why your review is different and therefore important; and it shows that you can interpret the literature to highlight contradictions and find gaps in the knowledge base that exists. Furthermore, it helps guard against accusations of plagiarism since previous authors' ideas are being acknowledged and it also stops you repeating and making the same mistakes as past studies.

\section{Muslims in Britain and Scotland}

Figures from the UK national census, 2001, show that 5\% of the population is comprised of Muslims making it the second largest religious group behind Christians [1]. If we compare that to the figure in Scotland's 2011 census, where Muslims only accounted for $1.4 \%$ of the population, we can see that this group was an even smaller minority then. However, the figures in Glasgow are more like that of the whole of the UK with $5 \%$ of the population comprising of Muslims and more than $40 \%$ of 
the Muslim population of Scotland residing there. Furthermore, $44.6 \%$ of the Scottish Muslim population is UK-born meaning that $54.4 \%$ were born outside of the UK. This statistic demonstrates that first-generation Muslims outnumber the second-generation.

The 2011 Census portrayed the situation of Muslims in Scotland rather more positively compared to UK Muslims. However, there were areas for concern. Muslims in Scotland were still more likely to be living in deprived areas. Unemployment was higher compared to in Scotland as a whole and Muslims had a higher number of households with dependent children. Health conditions were also generally worse, especially amongst women and the elderly. These factors can pose a threat regarding how Muslims relate themselves to the greater society. Therefore, it is necessary to study Muslim integration and how identity is formed since "identities may become sharpened by perceived inequalities in power and resources" [2].

\section{Muslim Integration}

Understandably, immigration is a stressful process in one's life. The challenges and problems of trying to become settled do not exist solely with the first-generation but are similarly experienced by future generations. Whilst the first-generation tries to cope with adjusting to a new culture, the second must attempt to integrate into society and at the same time develop their ethnic, religious and national identities. Throughout the world, many procedures and policies exist to assist immigrants in settling into a new society. Scotland, which presents itself as a multicultural society (albeit this representation is scrutinized constantly by politicians and the media alike), is no different. By way of assessing integration of immigrants in Scotland, tests such as the UK citizenship test and the English language test are in place. However, it is sometimes perceived that the function of these tests is to control immigration rather than to integrate immigrants [3]. Muslim integration into Western society is a widely discussed subject, both on social and political levels. With the introduction of the term 'Global Village', in the 1950 s, sociologists and psychologists postulated a series of conceptualizations about integration. [4] proposed integration as being one of the four primary modes of acculturation, along with assimilation, separation, and marginalization. He stated that integration is in operation when a person tries to maintain both their own culture and that of the host. With assimilation, an individual reject their original culture and adopts the culture of the host. In contrast, with separation, one maintains ties with the original culture and avoids contact of any sort with the host culture. Finally, marginalization is when an individual loses interest in maintaining his/her culture whilst also having little or no interest in mixing with the local culture. Through these four modes of acculturation, Berry declared that by using integration to acculturate, an individual experience less stress and becomes better adapted to life. Oppositely, in marginalization, one is most stressed and adapts poorly or even not at all to life in the host society. Berry also claimed that assimilation and separation fall somewhere in between integration and marginalization in terms of ability to adapt and experiences of stress.

Berry's model of acculturation has been applied by many researchers to better understand Muslim acculturation in various Western countries. For example [5] when making comparisons between how Muslim and non-Muslim immigrants in Belgium developed multiple identities and acculturated, discovered that the integration mode corresponded positively to Belgian and European identity but negatively corresponded to both groups' country of origin. Therefore, it can be said that through the integration mode of acculturation, Muslims related to their Belgian and European identity more than to their original identity. To give meaning to his conceptualization of the various eras of immigration to the US and the status Muslims hold there [6] drew on Berry's 'integration mode'. Accordingly, since a Muslim sees both his/her Islamic culture and the system in which they lead their lives as being more important than the host culture's, it is impossible for a Muslim to be bi-cultural. This concept that Muslims are unable to be bi-cultural seems rather extreme and far-fetched, taking into consideration [5] findings on how Muslim immigrants integrated themselves into Belgian culture. Shaub [6] later came to reflect on this in the same paper when he noted that in an era of connectivity (where the world is connected digitally, most prominently through the internet), it is easier for a Muslim to harmonize his/her own Islamic culture. Thus, it is possible to state that the 'integration mode' that Berry proposed is effective and useful when it comes to explaining how Muslims enter a new culture.

There are two major distinctions between Muslims and Westerners: religion and culture. However, these do not have to represent barriers to acculturation. There are many cases where immigrants completely adapt to the host country's culture and instances where the host culture is totally rejected. [7] posits that an individual's peer group plays a more important role than one's parents when it comes to forming the path of secondgeneration immigrants' acculturation. Through his research, he derived three modes of acculturation: Acculturation; Partial Acculturation; and De-acculturation. 'Acculturation' involves completely adopting the host country's culture and its way of life, to the extent of taking part in activities which Islam forbids. 'Partial Acculturation' comprises of those who, in order to conform to society and their parents' wishes, adapt somewhat to both cultures. 'De-acculturation' was said to be total obedience to one's religion, whilst rejecting the host culture [7]. applied this categorization along a spectrum of age, proposing that secondgeneration Muslims, who are in the mode of 'Acculturation' in their youth, latterly evolve to become 'Partially Acculturated' as a way of being more settled. Therefore, not only do they hold on to their 'Westernized' identity, but they also bring harmony to their lives by adhering to familial norms. Conversely, those Muslim youths who conform to 'De-acculturation' hold true to their beliefs and way of life as they get older. 
Here we can see that Ali's 'Partial Acculturation' and Berry's mode of 'Integration' share many similarities. It can be construed from these findings that there is no one defining process in which Muslim immigrants are acculturated and that being Muslim does not completely, and sometimes not at all, hinder one in adapting to a Western culture. It is important to recognize that, as research has shown, the process of forming identity in this context is interchangeable and contextualized. Identities are shaped based on the environment and context in which an individual lives and according to social norms that exist. Furthermore, identities have other significances and roles such as resistance, rebellion, and protection of one's ethnicity, and can often result in an individual taking on a hyphenated identity, as will be discussed later $[8,9]$.

Research regarding Muslim integration in the UK has borne mixed findings. Whilst some results indicate that much resistance exists, other research shows that there is an active desire to become integrated. However, upon reviewing this research, these varying results may be caused by a differentiation in method and sample. The research which demonstrates that Muslims are actively seeking to integrate is based on first-hand accounts of Muslims themselves whereas the data from official sources and reports has been created by non-Muslims. Examples of both types of research will now be examined. Taking the initial form of research mentioned above, in the cases where Muslims are asked about their own integration, it is apparent that they do not reject the idea but the way in which they view it can be complicated. From the viewpoint of Muslim Arabs in the UK, Nagel and [10] studied the process involved in integration and segregation. They concluded that this group considers interaction with the host society as important but instead of viewing integration as 'social cohesion', they think of it more as a discourse between diversified but equal communities who inhabit the same geographical space [11]. This implies that Muslims interpret the concept of integration differently compared to other residents in the UK. Similarly, [11] found that Muslims in Britain identified with Britishness and what it means to be British just as much as other groups. Additionally, discrimination played a part in forming their identities above all other socio-economic factors also stated that despite Muslims mainly residing in segregated neighborhoods, they feel part of the British community overall due to the materialization of integrated networks.

Adversely, research using national statistics data or from non-Muslim subjects, produces different results. Research was carried out by [12] to uncover patterns regarding the integration of Muslim immigrants into British society. Their results showed that regardless of the amount of time spent in the UK, Muslim immigrants still firmly held on to their religious identity. They were also viewed as being more impervious to cultural integration due to their unwillingness to use the English language. It was concluded by [12] that the system within which Muslims integrate in the UK is in direct contrast to the general concept of the UK's policy on immigration, i.e. economic attainment and geographical homogenization. Thus, by retaining their fervent religious identity, Muslim immigrants display more resistance to cultural integration. What's more, this pattern of integration was found to be more common amongst the bettereducated and more affluent Muslim immigrants who lived in more close-knit and well-to-do areas [12] This 'alienation' of Muslim immigrants in the UK was put down to the weaknesses of the government's integration policy [13]. [14] contradict this viewpoint by suggesting that failure to adapt well was due to perceived discrimination. However, through a mix of ethnic and national identity, Muslims were able to successfully adapt to the way of life in the host society. Research regarding the integration of Muslims into Western society, especially those living in the UK, has produced mixed results. There is an obvious need for more research to be done, specifically regarding how Muslims in Scotland integrate into society as the amount of research to draw upon in this area is limited. To further understand the mindset of Muslim immigrants, we will now look at the concept of identity and how it is formed, which is closely linked to integration.

\section{Formulation of Muslim Identity}

The configuration and reconfiguration of ethnic, religious and national identity is fundamental to the lives of immigrants. Much research has therefore been done regarding this topic in order to achieve a better understanding of how immigrants form their identities throughout the world. Researchers have concentrated on varying patterns and features of religious identity formation among young Muslim immigrants. For instance, a study by Chaudhury \& Miller [15]. looked at how young American Muslims of Bangladeshi descent developed religious identity and put forward two categories for this. The first group was called 'internal seekers. These are young Muslims who look within their faith to find answers. The second was called 'external seekers. This group looked to other faiths outside of Islam to get answers. Other contributory factors to their formation of identity were also uncovered in this study. Things such as praying five times per day; effective communication with family and peers; active participation in Muslim associations; and concentrating on present moment religious practices to ensure future rewards in life were factors. Likewise, Peek [16] proposed a three-phase formation of religious identity among young Muslim immigrants. He stated that religion as an identity was ascribed, chosen, and declared. The first phase tells us that Muslim children are primarily ascribed their religious identity. Then, after religious exploration, the child intentionally chooses to follow that religion. Finally, declared religious identity is adjudged to an identity formed on the back of the 9/11 attacks in New York in order to protect and maintain Muslim identity in response to discrimination [16]. 'religion as a chosen identity' phase appears like Chaudhury and Miller's [15] 'internal' and 'external' processes of seeking religion. Consideration must be given also to the contributory role that mosques play in 
influencing identity development and how, through teaching the Al-Qu'ran and through Islamic principles, social control is managed.

It can also be a very stressful process for first- and secondgeneration Muslim immigrants, in general, when it comes to developing identity. According to a study by Ostberg [17] young Norwegian Muslims of Pakistani backgrounds must engage in identity negotiation all through childhood and into adulthood. He goes on to explain that these negotiations involve questions such as: 'Who am I? What significance does be a Muslim and being a Norwegian citizen have? Which boundaries are negotiable, and which are unimaginable to traverse?' These negotiations are taking place amongst parents and children, between siblings, and inside peer groups [17]. Studies which look at Muslim women have been carried out. These women face challenges related to the re-creation of familiarity, ethnicity, and their work lives [18]. It was suggested by Marranci (2007) [19]. when looking at the case of identity amongst Muslim women in Northern Ireland, that emotion plays a key role in identity development. There was an overall feeling of insecurity among these women and, undeterred by their authoritarian male counterparts, a desire to form their own identity as Muslim women. By doing so, they were aided in conquering sentiments of isolation, seclusion, and displacement [19]. Further afield, [21]. looked at the identity of Muslim immigrant women in Australia and their perceptions of community. What they discovered was that religion played a key part and was at the core of developing a sense of community and in settling into life there. Other factors which affected how a sense of identity and community were formed and maintained were racism and ostracization; social support networks; and the role of gender. The study also indicated that the role of religion was a facilitator rather than a hindrance in integrating this group into society [21].

Research in the UK indicates that there is a mixed trend regarding identity development. There is no definitive evidence as to which identity is favored by Muslims who live here. For example, the feeling of national and religious identity amongst Muslims in Scotland was analyzed by Hopkins [22]. His study focused on two core themes: being Muslim and being Scottish [22]. posits that despite ties to ethnic culture existing, Muslims Scottish identity was preferred to their British or ethnic one [22]. claims that the main reasons for this were that they were born and bred in Scotland; they had been educated here; and they spoke with a Scottish accent. [22]. also states that their Scottishness has an association with sports football. From the mid-nineteenth century onwards, Scotland's national sport has been 'fitbaw' (football) and this is where Scottish nationalism is heightened, especially in matches between Scotland and the 'auld enemy'- England. These feelings of national identity correspond to the findings of the Labor Force Survey (200304). The evidence shows that around $65 \%$ of Muslims in Britain described themselves as English, Welsh, Scottish, or British as opposed to their ethnic identity. Also, more than 90\% of Britishborn Muslims described their national identity as British (Office of National Statistics, 2004) [20].

The effect of culture and community involvement on young Pakistanis was examined by Din [23]. It was found that secondgeneration Pakistanis preferred a British identity to a religious or ethnic one. Hyphenated identities such as British-Asian, Scottish-Asian, Pakistani-Scot were found to be more popular. Interestingly, young Muslims considered their parents to be 'less British' and 'more Pakistani'. The young people in Din's (2006) study felt more attached and better adjusted to the British way of life due to their language skills, length of stay, and their jobs. The results of this study do not stand alone. Previous research $[23,24]$ has shown that very few young Muslims describe their identities primarily as 'Asian', with most considering themselves to be 'British'. This is reflected in how they look, the way they socialize, and how they entertain themselves [25] Similarly, [26]. tells us that many young Muslims in Britain are searching for answers about whether they belong in an 'Islamic' community or in a British one. He goes on to note that they are redeveloping their understanding of belonging regarding nationality, ethnicity, and religion, and are negotiating new methods of being Muslim in Britain. On the other hand, Jacobson [27]. argues that young British-Pakistani-Muslims regard religious identity as being more important than an ethnic one due to the universalism of ethnicity and religion. Furthermore, he stated that Muslims consider nationalism to be taboo according to Islam so expressed their loyalty and sense of belonging to a Muslim Ummah (Global Muslim Community). The difference between what is right and what is wrong, according to Jacobson [27] is clearly stated within Islam. Muslims perceive this to be less defined if one identifies with ethnicity and thus, they choose to identify with their religion instead [27]. The concept of Muslim Ummah also displays a Muslim's necessity to be part of a global brotherhood in response to their 'alien' status and from living in a country where they are a minority. This was demonstrated by [28]. who noted in their study regarding Scottish Muslims that when presented with the option they opted for hyphenated identities? However, when they were only allowed to choose one option, they chose their Muslim identity over all others. This coincides with what was discussed in the previous section regarding integration, i.e. that there is at present no conclusive results in the research which indicates which identity Muslims have adopted as their preferred one(s)

\section{Irish Identity and Celtic FC in Scotland}

Hoberman [29] notes that "sport has no intrinsic value structure, but [it] is a ready and flexible vehicle through which ideological associations can be reinforced" while, for his part, Hobsbawm [30] declares that "the identity of a nation of millions seems more real as a team of eleven named people". We can take these observations to mean that sport can incorporate and convey identity and community - socially, politically, ethnically, 
culturally, religiously, nationally, and even economically in a form unlike almost any other social manifestation. Celtic FC, a professional football team from Glasgow, Scotland, is a demonstration of these assertions, encompassing community involvement and supporter associations affiliated with Scottish football. As Robert Kelly (ex-Chairman of Celtic FC) once said, "[t]his Celtic Football Club is much more than a football club, to a lot of people it's a way of life."

Founded by Irish-Catholic immigrants in [33]. the role that Celtic FC plays and has played in forming cultural and ethical identity of their supporters is important on many levels. As Devine (2000)[33] posits, until very recently, the Irish community in Scotland has not "been effectively integrated into the wider study of Scottish historical development". However, that which has been neglected in research has received attention through the Scottish media. Sport can replicate and reflect ethnic and national uniqueness as well as mirror social tensions and divisions. While most of the discourse is about Scotland as 'one people', on a range of cultural and identity designators, "the case of Celtic demonstrates how that dominance is manufactured as a social reality and norm by discounting, marginalizing, demeaning, or corrupting minority distinctiveness and difference" [32].

For second- and third-generation Irish communities for whom being white, having a local accent, and supposed cultural affinities have customarily been taken to reflect a population easily assimilated to the 'white' Scottish majority, the unwavering Irish identity of the fans of Celtic FC and the club itself contests these assumptions Modood (1996) [35]. Through supporting and following Celtic, the reproduction, preservation, and expression of Irishness in Scottish society is realized, and, therefore, it is significant for comprehending the various diverse means by which identity is formed in the multi-ethnic Britain of today. This takes place within the context of continuing debates regarding multiculturalism in Britain, in general; and, within lively and occasionally rancorous debates about the controversial topic of sectarianism within Scottish society [33]. A great deal of the research conducted in this area came from the Irish 2 Project which was undertaken in the early-2000s. This sociological enquiry considered the problems of identity among those born in Britain but with at least one parent or grandparent born in Ireland. On top of this research, a web-based analysis over a period since 1990 of all the major newspapers in Scotland demonstrates that the discourses and narratives presented in this media problematize Irish pride and the Irish identity of Celtic FC and its fans. Hundreds of direct and indirect remarks about Celtic as well as many, many more in other media channels makes it evidently clear that a certain type of commentary is foremost, all-encompassing, and perpetual, weaving its way through editorials, newspaper columns, magazine articles, radio debates, and TV interviews [32].

To sum up, discourses that are profoundly disparaging of Celtic FC's Irishness are embedded and ingrained within Scottish society. According to Conner [34] while the origins of socially constructed identity links are important to comprehend, "these identities are being performed, maintained, and renegotiated on an everyday basis, (and) provide a more complete understanding of collective identities in today's globalized world." He goes on to conclude that the reasons and motivations for people all over the world to support a football team from Scotland are not as simple as one might first imagine and are repeatedly reformed and realigned across the spectrum of space and time [34].

\section{Conclusion}

From the review of the literature, identity is a complex subject and is formed differently according to age, sex, generation, feelings of togetherness or otherness, religion, amongst other things. Muslims in Britain are still not fully integrated into British society and probably never will be due to their strong cultural traditions and religious beliefs. Similarly, the Irish population of Scotland still does not feel Scottish enough to renounce its Irish identity, which may only be evident through its members' grandparents' or even great-grandparents' birthplaces. Since both groups possess a concept of being outsiders and are minorities, they share a common bond. Research in the form of interviews and questionnaires would need to be performed in order to gain a better insight into whether these similarities are the defining factors as to why Scottish Muslims choose to support Celtic, or if there are other drivers such as peer-group pressure, geography (i.e. closeness to Celtic's home stadium, Parkhead), search for glory, or even down to the simple explanation that one of our Pakistani-Scot friends told us when he said: "The Celtic flag is green and white. The Pakistan flag is also green and white. So, I support Celtic."

\section{References}

1. Office of National Statistics (2013) Full story: What does the Census tell us about religion in 2011.

2. Kabir AN (2010) Young British Muslims: Identity, Culture, Politics and the Media. Edinburgh: Edinburgh University Press 1-256.

3. Etzioni A (2007) Citizenship tests: A comparative, communitarian perspective. The Political Quarterly 78(3): 353-363.

4. Berry JW (1997) Immigration, acculturation and adaptation. Applied Psychology: An International Review 46(1): 5-34.

5. Saroglou V, Mathijsen F (2007) Religion, multiple identities and acculturation: A study of Muslim immigrants in Belgium. Archive of the Psychology of Religion 29: 177-198.

6. Shaub MH (2007) Acculturation of immigrants in America: Where do Muslims fit in? Paper presented at the Perils of empire: Islamophobia, religious extremism and the new imperialism. The Department of Government and Politics 226 University of Maryland, College Park, Maryland.

7. Ali S (2008) Understanding acculturation among second-generation South Asian Muslims in the United States. Contributions to Indian Sociology 42(3): 383-411.

8. Hopkins P (2007) Blue squares, proper Muslims and transnational networks: Narratives of national and religious identities amongst young Muslim men living in Scotland. Ethnicities 7(1): 61-81. 
9. Kadianaki I (2010) Commentary: Making sense of immigrant identity dialogues. Culture Psychology 16(3): 437-448.

10. Nagel CR \& Staeheli LA (2008) Integration and the negotiation of 'here' and 'there': The case of Britain Arab activist. Social and Cultural Geography 9(4): 415-430.

11. Maxwell R (2006) Muslims, South Asians and the British mainstream: A national identity crisis. West European Politics 29(4): 736-756.

12. Bisin A, Patacchini E, Verdier T, Zenou Y (2007) The specific patterns of Muslim immigrants' integration in the UK.

13. Joppke C (2009) Limits of integration policy: Britain and her Muslims. Journal of Ethnic and Migration Studies 35(3): 453-472.

14. Vedder P, Sam DL, Liebkind K (2007) The acculturation and adaptation of Turkish adolescents in North-Western Europe. Applied Development Science 11(3): 126-136.

15. Chaudhury SR, Miller L (2008) Religious identity formation among Bangladeshi American Muslim adolescents. Journal of Adolescent Research 23(4): 383-410.

16. Peek L (2005) Becoming Muslim: The development of a religious identity. Sociology of Religion 66 (3): 215-242.

17. Ostberg S (2003) Norwegian-Pakistani adolescents: Negotiating religion, gender, ethnicity and social boundaries. Young 11(2): 161181.

18. Hattar-Pollara M, Meleis IA (1995) The stress of immigration and the daily lived experiences of Jordanian immigrant women in the United States. Western Journal of Nursing 17(5): 521-539.

19. Marranci G (2007) Migration and the construction of Muslim women's identity in Northern Ireland. In C. Aitchison, P. Hopkins, \& M. Kwan (Eds.), Geographies of Muslim identities. London: Ashgate Publishing Limited 79-92.

20. Office of National Statistics. (2013). Full story: What does the Census tell us about religion in 2011?

21. Fijac BM, Sonn CC (2004) Pakistani-Muslim immigrant women in Western Australia: Perceptions of identity and community. Network, The Journal of the College of Community Psychologists 16: 18-27.
22. Hopkins $P$ (2007) Blue squares, proper Muslims and transnational networks: Narratives of national and religious identities amongst young Muslim men living in Scotland. Ethnicities 7(1): 61-81.

23. Din I (2006) The new British: The impact of culture and community on young Pakistanis. Hampshire: Ashgate Publishing Limited.

24. Ghuman S (1999) Asian adolescents in the west. Leicester: The British Psychological Society 146: 121-135.

25. Modood T, Berthoud R, Lakey J, Nazroo J, Smith P, et al. (1997) Ethnic Minorities in Britain: Diversity and Disadvantage. London: Policy Studies Institute.

26. Ansar H (2002) Muslims in Britain. London: Minority Rights Group International.

27. Jacobson J (1997) Religion and ethnicity: Dual and alternative sources of identity among young British Pakistanis. Ethnic and Racial Studies 20(2): 238-256.

28. Saeed A, Blain N, Forbes D (1999) New ethnic and national questions in Scotland: Post-British identities among Glasgow Pakistani teenagers. Ethnic and Racial Studies 22(5): 821-844.

29. Hoberman J (1984) Sport and Political Ideology. London: Heinemann.

30. Hobsbawm E (1990) Nations and Nationalism Since 1780: Programme, Myth, Reality. Cambridge: Cambridge University Press.

31. Saeed A, Blain N, Forbes D (1999) New ethnic and national questions in Scotland: Post-British identities among Glasgow Pakistani teenagers. Ethnic and Racial Studies 22(5): 821-844.

32. Bradley JM (2008) Celtic Football Club, Irish ethnicity, and Scottish society. New Hibernia Review 12(1): 96-110.

33. Devine TM (2000) Scotland's Shame: Bigotry and Sectarianism in Modern Scotland Edinburgh: Mainstream.

34. Conner N (2014) Global cultural flows and the routes of identity: the imagined worlds of Celtic FC, Social \& Cultural Geography 15(5): 525-546.

35. Modood, T. (1996). The changing context of 'race' in Britain: A symposium, Patterns of Prejudice, Vol. 30 (1), pp. 3-13.

\section{Your next submission with Juniper Publishers} will reach you the below assets

- Quality Editorial service

- Swift Peer Review

- Reprints availability

- E-prints Service

- Manuscript Podcast for convenient understanding

- Global attainment for your research

- Manuscript accessibility in different formats

( Pdf, E-pub, Full Text, Audio)

- Unceasing customer service

Track the below URL for one-step submission

https://juniperpublishers.com/online-submission.php 